\title{
A New Bioassay Method for Evaluation Allelopathic Potential of Rice Germplasm
}

\author{
Yongliang $\mathrm{Lu}^{1}$, Hong $\mathrm{Lu}^{2}$, Kilung $\mathrm{Kim}^{3}$, Yiding $\mathrm{Sun}^{4}$, Jian $\mathrm{Fu}^{4}$ and Yiqing $\mathrm{Guo}^{2}$ \\ 1. China National Rice Research Institute, Chinese Academy of Agricultural Sciences, Hangzhou 310006, China \\ 2. National Center for Agro-Biodiversity/Yunnan Agricultural University, Kunming 650201, China \\ 3. College of Agriculture and Life Science, Kyungpook National University, Daegu 702-701, Korea \\ 4. Biotchnology \& Germplasm Resource Institute, Yunnan Academy of Agricultural Sciences, Kunming 650223, China
}

\begin{abstract}
Allelopathy was defined in 1996 by IAS (international allelopathy society) as any process involving secondary metabolites produced by plant, algae, bacteria and fungi that influences the growth and development of agricultural and biological systems. Rice allelopathy against weeds was reported since 1989, which offers an integrated weed management with substantially reduced herbicide usage. Application of allelopathic rice cultivars is thought a resources conservation and environmental friendly way of weed bio-control, and could promote the sustainable development of agriculture. Screening or evaluating the allelopathic potential rice variety is the first step. In this paper, a new bioassay method was set up by the allelopathic potential of 9 rice lines on the target weed barnyardgrass (Echinochloa crusgalli), and comparing with bioassay methods such as relay seeding in filter paper (RSF) and relay seeding in agar (RSA). The results indicated that three methods had a same tendency in evaluating the allelopathic potential of rice; there existed a significant difference among different bioassay methods, and an interaction between bioassay methods and rice lines. The method of root exudates (RE) with the highest value and a correlation efficiency of 0.98 was considered as ideal bioassay method for evaluation of allelopathic potential.
\end{abstract}

Key words: Rice, allelopathic potential, bioassay methods, comparison.

\section{Introduction}

The word allelopathy from the Greek words 'allelon' means mutual and 'pathos' means harm or affection. Rice [1] defined allelopathy as the effect of one plant (including microorganisms) on growth of another plant through the release of chemical compounds into the environment. The plant releasing allelochemicals is referred to as donor plant, and the plant being influenced is considered as the target of afflicted plant.

Research on allelopathy in rice started in the United States in the late 1980s [2]. With increasing labor costs, availability of herbicides, and change of rice planting pattern from transplanting to direct seeding, rice production became highly depending on herbicides.

Corresponding author: Yiqing Guo, Ph.D., professor, research field: plant growth and regulation.
The magnitudes of weed problems in rice and increased environmental concerns about pesticide use have been the driving forces behind this research. It is indisputable to find an alternative way of weed control for the sustainable. Allelopathy in rice may be one of the potential biological ways to weed management. Screening or evaluating the allelopathic rice ability is the first step. Allelopathic activity is initially assessed by phenotype, which can be categorized as field or laboratory screening. In the past decades, various laboratory screening techniques has been developed to demonstrate, measure and qualify allelopathic effect regarding donor species, target species, test medium, developmental stage, or response parameters, such as germination test [3], growth test [4, 5], agar medium selection method [6, 7], water extraction method $[8,9]$, 24-well culture plate microbioassay [10], relay seeding technique [11], cluster analyses using HPLC 
[12], which can be divided into aqueous extract and seedling screening. The spectrum of bioassays suggests that seedling of allelophic effect is probably too complex for a single bioassay. For example, to establish definite bioassays for different species eliminate competition to nutrients, avoid microbial breakdown of compounds, test whole plants or plant extracts all require different experimental protocols. Thus, bioassays are not standardized, which makes it difficult to parallel compare the results. If the chemical basis for the effect is known, precious chemical screening of germplasm is probably the favored approach.

In this study, allelopathic and non-allelopathic rice varieties were used to compare several bioassay methods in previous experiment to determine a best, cheap, easy, reliable and universal bioassay method for allelopathic effect screening in rice.

\section{Materials and Methods}

\subsection{Materials}

Nine rice lines from different country were used, which evaluated in a previously study shown as allelopathic, and non-allelopathic effects (Table 1).

\subsection{Experimental Design for Comparison of Bioassay Methods}

Rice as donor plant, and barnyardgrass as target plant, three bioassay methods were used to test the allelopathic potential in two factors randomized design with 3 replications.

\subsubsection{Relay Seeding in Filter Paper (RSF)}

Modified relay seeding method [11] was followed. Twenty rice seeds sterilized and pre-germinated were sown on filter paper in Petri-dish in two rows. The dish was placed in a container with $50 \mathrm{~mL}$ sterilized water (keeping the same volume during experimental time) using filter paper bridge to keep it moist, and allowed to grow in growth chamber at $25{ }^{\circ} \mathrm{C}$ at night, and $30^{\circ} \mathrm{C}$ in day for 7 days, $8 \mathrm{~h}$ dark and $16 \mathrm{~h}$ light. 15 seeds of BYG were seeded (pre-germination) in the middle row. Rice and BYG grew together for 5 days; the 10 longest root lengths of BYG were measure respectively.

\subsubsection{Relay Seeding in Agar (RSA)}

This is named as equal-compartment-agar-method [17]. Petridish was pre-filled with $0.3 \%$ water agar, 12 germinated rice seeds aseptically were sown on an agar surface in three rows (3-4-5) on one half part of the petri-dish $(5 \mathrm{~cm}$ in deep and $9 \mathrm{~cm}$ in diameter), then the dishes were placed in culture room at 25-28 ${ }^{\circ} \mathrm{C}$ under light condition. After 7 days, sterilized and pre-geminated 12 seeds of barnyardgrass were sown in the other part of the dish, and 1 piece of pre-autoclaved white paper board was inserted across the centre and down the middle of the petridish, which was thereby divided into two equal compartments, each occupied separately by rice and barnyardgrass seedling. The petridish were again placed back in the cultural room under the same condition growth together for 5 days; the longest root length of 5 seeding were measured.

Table 1 Rice accessions used in study.

\begin{tabular}{|c|c|c|c|c|}
\hline Rice lines & Country of origin & Type or species & Allelopathic potential & Rice lines supplied by \\
\hline Kouketsumochi & Japen & O. sativa. Japonica & $\mathrm{Y}^{[13]}$ & \multirow{3}{*}{$\begin{array}{l}\text { Kyungpook National } \\
\text { University, Korea }\end{array}$} \\
\hline Lemont & USA & O. sativa. Japonica & $\mathrm{N}^{[14]}$ & \\
\hline PI312777 & USA & O. sativa. Japonica & $Y^{[14]}$ & \\
\hline Yunlu28 & China & O. sativa. Japonica & $\mathrm{Y}^{[15]}$ & \multirow{6}{*}{$\begin{array}{l}\text { Yunnan Academy } \\
\text { Agriculture Sciences, } \\
\text { China }\end{array}$} \\
\hline Yaas11002 & Africa & O. glaberima (IGRC 100127) & $Y^{[16]}$ & \\
\hline Zinuo & China & O. sativa. Indica & $\mathrm{U}$ & \\
\hline Huangkenuo & China & O. sativa. Indica & $\mathrm{Y}^{[16]}$ & \\
\hline Weixihonggu & China & O. sativa. Japonica & $\mathrm{U}$ & \\
\hline Weixiziguo & China & O. sativa. Japonica & $\mathrm{U}$ & \\
\hline
\end{tabular}

*Y, yes; N, no; U, unknown. 


\subsubsection{Rice Root Exudates (RE)}

Modified equal-compartment-agar-method [17] was followed. Petridish was pre-filled with $0.3 \%$ water agar. The rice seed was aseptically and homogeneously sown on the agar surface, the dish was placed in the culture room in the same condition as above mentioned. After 12 days, all rice plant were removed, 12 sterilized and pregeminated barnyardgrass seeds were sown on the agar surface. Seedling grew in same condition for 5 days, and the longest root length of 5 seedling were measured.

The allelopathic potential was evaluated by inhibitory rate (IR), and calculated as following: IR = $(1-\mathrm{Tr} / \mathrm{ck}) \times 100$. $\mathrm{Tr}$ is the root length of treatment; ck is the root length of controlled. Barnyardgrass grows along as control. When IR $<0$, it means stimulatory effects; when IR $>0$, it means the inhibitory effects.

\subsection{Data Analysis}

Bioassay methods comparison: Two factors randomized design with 3 replications, in which bioassay methods as A factor, 9 rice lines as B factor was carried out. The data were analyzed by DPS (6.50) program.

\section{Results and Discussion}

\subsection{Comparison of Bioassay Methods}

The results indicated in table 2 where there existed a significant difference among different bioassay methods, and the same rice line had a different allelopathic potential depending on bioassay methods employed. So that there was an interaction between bioassay methods and rice lines.

The results in table 3 showed that three methods,
RSF, RSA and RE showed a similar trend in evaluating the allelopathic potential of rice. However, the inhibitory rate was different among rice lines and bioassay methods. The method of RSF showed the highest inhibitory rate while the method of RSA exhibited the lowest inhibitory rate. As an exception, rice lines of Weixizigu and Huangkenuo had a higher inhibitory rate in the method of RE. Additionally, Zinuo in the method of RSA had a higher inhibitory rate than in the other methods. The correlation analysis between bioassay methods and the average inhibitory rate showed a significant correlation (Table 4). The method of RE had the highest value and a correlation efficiency of 0.98 , hence RE was thought as the best bioassay method for evaluation of rice allelopathic potential.

\subsection{Comparison of Allelopathic Potential among Rice Lines}

Different inhibitory rate was observed among all nine rice lines depending on the bioassay method used. The data were showed in table 3 . The line of Weixihonggu and Weixizigu showed the highest average inhibitory rate as $50.8 \%$ and $41.75 \%$ respectively, followed by Huangkenuo; Yaas 11002; Kouketsumochi, Zinuo and Yunlu28; and then PI312777. Lemont had the lowest average inhibitory rate, even though it had a stimulative effect under the RSA method. The results indicated that if the inhibitory rate was higher in the method of RSF and RE, the average inhibitory rate of three bioassay methods was also higher. And there existed an interaction between rice lines and bioassay methods. The line of PI312777, Weixihonggu and Weixizigu showed a higher inhibitory rate in the

Table 2 Analysis of variance (ANOVA).

\begin{tabular}{llllll}
\hline Variance source & square sum & df & Average of variance & F & P \\
\hline A factor & 0.5490 & 2 & 0.2745 & 34.8970 & 0.0001 \\
B factor & 1.1408 & 9 & 0.1268 & 16.1140 & 0.0001 \\
A x B & 0.5698 & 18 & 0.0317 & 4.0240 & 0.0004 \\
Error & 0.2360 & 30 & 0.0079 & & \\
Total & 2.4956 & 59 & & & \\
\hline
\end{tabular}


Table 3 Significant comparison of root-length inhibition between rice lines and bioassay methods.

\begin{tabular}{llllll}
\hline \multirow{2}{*}{ Rice lines name } & \multirow{2}{*}{ Experimental code } & $\begin{array}{l}\mathrm{RSF}(\mathrm{IR}) \\
\mathrm{X}_{1}\end{array}$ & $\begin{array}{l}\mathrm{RSA}(\mathrm{IR}) \\
\mathrm{X}_{2}\end{array}$ & $\begin{array}{l}\text { RE(IR) } \\
\mathrm{X}_{3}\end{array}$ & $\begin{array}{l}\text { Average } \\
\text { Y }\end{array}$ \\
\hline Kouketsumochi & 1 & 25.50 & 6.80 & 13.25 & $15.18 \mathrm{~cd} \mathrm{BCD}$ \\
Lemont & 2 & 27.20 & -10.70 & 3.75 & $6.75 \mathrm{de} \mathrm{DE}$ \\
PI312777 & 3 & 43.50 & -12.75 & 10.43 & $13.73 \mathrm{~cd} \mathrm{CD}$ \\
Yunlu28 & 4 & 27.20 & 1.75 & 26.25 & $18.40 \mathrm{bc} \mathrm{BCD}$ \\
Yaas11002 & 5 & 35.25 & -4.70 & 28.00 & $19.52 \mathrm{be} \mathrm{BC}$ \\
Zinuo & 6 & 19.35 & 21.20 & 16.40 & $18.98 \mathrm{bc} \mathrm{BCD}$ \\
Huangkenuo & 7 & 27.15 & 22.15 & 33.10 & $27.47 \mathrm{~b} \mathrm{~B}$ \\
Weixihonggu & 8 & 66.90 & 24.10 & 61.40 & $50.80 \mathrm{a} \mathrm{A}$ \\
Weixizigu & 9 & 46.35 & 25.30 & 53.60 & $41.75 \mathrm{a} \mathrm{A}$ \\
Ck & 10 & 0.00 & 0.00 & 0.00 & $0.00 \mathrm{e} \mathrm{E}$ \\
\end{tabular}

* The data in this table was average of 2 replications. The small letter indicated significant at $5 \%$ level, whereas the capital letter represented significant at $1 \%$ level.

Table 4 Correlation analysis between bioassay methods and average IR.

\begin{tabular}{lllll}
\hline Correlation efficiency & $\mathrm{RSF}\left(\mathrm{X}_{1}\right)$ & $\mathrm{RSA}\left(\mathrm{X}_{2}\right)$ & $\mathrm{RE}\left(\mathrm{X}_{3}\right)$ & Average $\mathrm{Y}$ \\
\hline $\mathrm{X}_{1}$ & 1.0000 & 0.2800 & $0.79^{* *}$ & $0.83^{* *}$ \\
$\mathrm{X}_{2}$ & 0.2800 & 1.0000 & $0.72^{*}$ & $0.75^{* *}$ \\
$\mathrm{X}_{3}$ & $0.79^{* *}$ & $0.72^{*}$ & 1.0000 & $0.98^{* *}$ \\
average & $0.83^{* *}$ & $0.75^{* *}$ & $0.98^{* *}$ & 1.00 \\
\hline
\end{tabular}

$* P<0.05 * * P<0.01$.

method RSF, but PI312777 had a very lower effect in the method of RSA and RE. Weixizigu showed a highest inhibitory rate under RE method, which was a reverse result in comparison with other rice line. These results might be due to competition between rice and barnyardgrass in the RSF method, or the parameter measured as longest root-length.

\subsection{Discussion and Conclusion}

Screening or evaluating the allelopathic potential of rice is the first step in crop allelopathy. Setting up efficient and reasonable bioassay technique is the basis for further research. Many scientists [17-19] stressed the importance of the bioassay method having a cheap, easy to manipulate, reliable and universal. In this research, the famous methods of RSF and RSA which have been used for screening allelopathic potential of rice variety and a new method of RE were compared by a diversify rice germplasm including species of Oryza sativa and O. glaberima (Yaas11002), indica and japonica types, also upland rice (YunLu28) and high altitude paddy rice (Weixihonggu and Weixizigu distribution in 2,650 meter above sea level). This experimental results indicated that the three methods had the same tendency to evaluate rice allelopathic potential (Table 3) though there were different root inhibitory rate among them. In the method of RSA, the inhibitory rate was less than zero which means a stimulative effect. This result might be due to the fact that rice and weed were separated as two parts although it was better to avoid competition between two species of plants. Another was attributed to measurement of the longest root-length, which might have much lower effect or no any effect of rice. In the other words, this might have resulted from escape of rice suppression. Furthermore, in the method of RSF, barnyardgrass seeds were sown 7 days later than that of rice seed, which resulted in a stronger competitive ability of rice and combining with the competitive and allelopathic effects.

Some scientists believe that agar medium is a very good material for bioassay of allelopathic potential 
evaluating $[6,20,21]$. The $0.3 \%$ agar medium has sufficient water to keep a better moisture condition, and hard enough to support good development of root system. The best results was showed in RE method which might be due to the $0.3 \%$ agar medium employed to couple with eliminating competition for nutrients among different species of plant and microbial breakdown of compounds. And more, the results might directly reflect the root exudates from rice.

A reasonable bioassay method is very important to the result of screening, especially to identify the inheritable characteristics or 'traits' of rice. Some studies on analysis the QTLs associated with allelopathic effects showed that there are a few consistent with main-effect QTLs regions, and significant difference among them [22-25], which might result from test plant and different bioassay methods. Writers believe that the method of rice root exudates (RE) is a reasonable bioassay method, and ideally suited to magnitudes screening in laboratory.

\section{Acknowledgments}

We would like to thanks Prof. Tao Dayun in yunnan Academy of Agricultural Sciences for providing rice lines.

\section{References}

[1] Rice, E. L. 1984. Allelopathy. 2nd ed. Orlando (Fla., USA); Academic Press.

[2] Dilday, R. H., Nastasi, P., and Smith, R. J. 1989. "Allelopathic Observation in Rice (Oryza sativa L.) to Ducsalad (Heteranthera limosa)." Proceedings of the Arkansas Academy of Sccience 43: 21-22.

[3] Pande, P. C., Dublish, P. K., and Jain, D. K. 1980. "Effect of Extracts of Argemone mexicana Linn. on Seed Germination and Seedling Growth of Abelmoschus escultentus." Ser. Bangl. J. Bot. 9: 67-71.

[4] Bastiaans, L., Kropff, M. J., Kempuchetty, N., Rajan, A., and Migo, T. R. 1997. "Can Simulation Models Help to Design Rice Cultivars that Are More Competitive sgainst Weds?" Field Crops Research 51: 101-11.

[5] Kropff, M. J., Lotz, L. A. P., and Weaver, S. E. 1993. "Practical Applications in Modeling Crop-weed Interactions.” Eds. M. J. Kroff and H. H. van Laar, CAB
International and Los Banos, Wallingford, UK, International Rice Research Institute, Philippines, 1993, pp. $149-68$.

[6] Fujii, Y. 1992. "The Potential Biological Control of Paddy Weeds with Allelopathy: Allelopathic Effect of Some Rice Varieties." In Proc. Int. Symposium on Biological Control and Integrated Management of Paddy and Aquatic Weeds in Asia. Tsukuba, Japan. National Agricultural Research Center 1992, pp. 305-20.

[7] Wu, H., Pratley, D., Memerle, T., and Haig, T. 1999. "Crop Cultivars with Allelopathic Capability." Weed Res. 39: 171-80.

[8] Ebana, K., Yan, W. G., Dilday, R. H., Namai, H., and Okuno, K. 2001a. "Variation in the Allelopathic Effect of Rice with Water Soluble Extracts." Agron. J. 93: 12-6.

[9] Kim, K. U., Shin, D. H., Kim, H. Y., Lee, I. J., and Olofsdotter, M. 1999. "Evaluation of Allelopathic Potential in Rice Germplasm.” Korean J. of Weed Sci. 9 (2): 1-9.

[10] Rimando, A. M., Olofsdootter, M., Dayan, F. E., and Duke, S. O. 2001. "Searching for Rice Allelochemicals: An Example of Bioassay Guided Isolation." Agron. J. 93: 16-20.

[11] Navarez, D., and Olofsdotter, M. 1996. "Relay Seeding Technique for Screening Allelopathic Rice (Oryza sativa)." In: H. Brow et al. (ed.) Proc. Second International Weed Control Congress, Copenhagen, Denmark. P 1285-90.

[12] Mattice, J. D., Dilday, R. H., Gbur, E. E., and Skulman, B. W. 2001. "Barnyardgrass Growth Inhibition with Rice using High-Performance Liquid Chromatography to Identify Rice Accession Activity.” Agron. J. 93: 8-11.

[13] Kim, K. W., Kim, K. U., Shin, D. H., Lee, I. J., Kim, H. Y., Koh, J. C., and Nam, S. H. 2000. "Searching for Allelochemicals from the Allelopathic Rice Cultivar, Kouketsumochi." Korean J. of Weed Sci. 20 (3): 197-207.

[14] Dilday, R. H., Lin, J., and Yan, W. G. 1994. "Identification of Allelopathy in the USDA-ARS Rice Germplasm Collection." Australian J. of Exp. Argi. 34: 907-10.

[15] Zhang, F. D., Guo, Y. Q., Yu, L. Q., and Tao, D. Y. 2004b. "The Study on Bioassay for Rice Allelopathy to Barnyardgrass." China J. of Huazhong Agricultural Unversity 23 (2): 203-7.

[16] Zhang, F. D., Guo, Y. Q, Yu, L. Q., and Tao, D. Y. 2004a. "Evaluation and Screening of Resistance to Barnyardgrass in Germplasm of Wild Rice (Oryza sativa) and African Cultivar." Chinese J. of Acta Agrinomica Sinica 30 (11): 1140-4.

[17] Wu, H., Pratley, D., Memerle, T., and Haig, T. 2001. "Screening Methods for the Evaluation of Crop Allelopathic Potential." Bot. Rev. 67 (3): 171-80. 
[18] Olofsdotter, M. 2001. "Rice-A Step toward Use of Allelopathy." Agron J. 93: 3-8.

[19] Kim, K. U., and Shin, D. H. 2008. "Progress and Prospect of Rice Allelopathy Research//Zeng R S, ed. Allelopathy in Sustainable Agriculture and Forest [M]." New York: Springer: 189-213.

[20] Pederson, G. A. 1986. "White Clover Seed Germination in Agar Containing Tall Fescue Leaf Extracts." Crop Sci. 26: $1248-9$

[21] Wu, H., Pratley, D., Memerle, T., and Haig, T. 2000. "Evaluation of Seedling Allelopathy in 453 Wheat (Triticum aestivum) Assecion against Annual Ryegrass (Lolium rigidum) by the Equal-compartment-agar Method." Agric. Res. Aust. 51: 937-44.
[22] Ebana, K., Yan, W. G., Dilday, R. H., Namai, H., and Okuno, K. 2001b. "Analysis of QTLs Associated with the Allelopathic Effect of Rice using Water-soluble Extracts." Breeding Sci. 51: 47-51.

[23] Jensen, L. B., Courtois, B., Shen, L., Li, Z., Olofsdotter, M., and Mauleon, R. P. 2001. "Location Genes Controlling Rice Allelopathic Effects against Barnyardgrass in Upland Rice.” Agron. J. 93 (1): 21-6.

[24] Xu, Z. H., He, Y., Cui, S. R., and Zhao, M. 2003. "Genes Mapping on Rice Allelopathy against Barnyardgrass." China J. Appl. Ecol. 14 (12): 2258-60.

[25] Zen, D. L., Qian, Q., and Teng, S. 2003. "Gentic Mechanisms on Rice Allelopathic." China Sci. Bell 48 (1): 70-3. 